\title{
Microwave Irradiation Effect on the Ligand Exchange Reaction between Ferrocene and Heterocycles
}

\author{
Yutaka Okada, Atsushi Niou, Shinya Nakano \\ Department of Applied Chemistry, Ritsumeikan University, Kyoto, Japan \\ Email: ygvictor@sk.ritsumei.ac.jp
}

How to cite this paper: Okada, Y., Niou, A. and Nakano, S. (2017) Microwave Irradiation Effect on the Ligand Exchange Reaction between Ferrocene and Heterocycles. Green and Sustainable Chemistry, 7, 95-100.

https://doi.org/10.4236/gsc.2017.72008

Received: January 18, 2017

Accepted: March 12, 2017

Published: March 15, 2017

Copyright (c) 2017 by authors and Scientific Research Publishing Inc. This work is licensed under the Creative Commons Attribution International License (CC BY 4.0).

http://creativecommons.org/licenses/by/4.0/

\begin{abstract}
The ligand exchange reaction is a typical reaction of ferrocenes. This reaction proceeds via the abstraction of a cyclopentadienyl ring by a Lewis acid followed by coordination of an aromatic compound to the resulting species. This reaction with conventional heating requires a long reaction time. Furthermore, the reactions with heterocycles are lower than those with the corresponding hydrocarbons, and do not produce any products in some cases. In this paper, the ligand exchange reaction of ferrocene and a heterocyclic aromatic compound during microwave irradiation and its effect are discussed. As a result, for some heterocycles, the decrease in the reaction time was confirmed. Furthermore, under the microwave irradiation conditions, the tendency in which the difference in their reactivities became low was confirmed.
\end{abstract}

\section{Keywords}

Microwave Irradiation Effect, Ferrocene, Ligand Exchange, Heterocycle

\section{Introduction}

Ferrocene has an aromaticity, and undergoes a great variety of reactions. One of them is the ligand exchange reaction with aromatic compounds. This reaction easily proceeds when ferrocene and arenes are heated with aluminum chloride in suitable solvents [1]. The reaction mechanism is as follows: 1) aluminum chloride coordinates at the $\pi$-electron of the cyclopentadienyl ring, and pulls out the ring; 2) the formed [Cp-Fe] $]^{+}$moiety combines with the arene (Scheme 1) [2].

On the other hand, it is known that various kinds of organic reactions are accelerated by microwave irradiation [3]. The authors reported a remarkable reaction accelerating effect by the microwave irradiation for the ligand exchange 


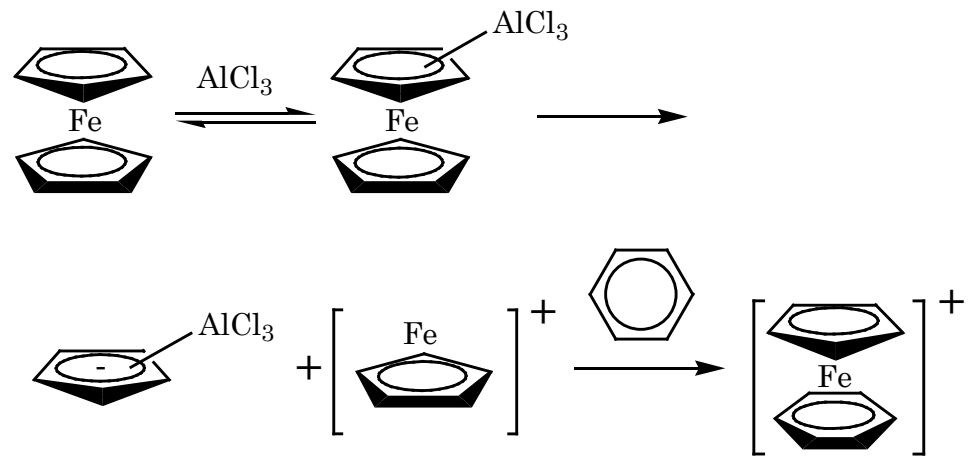

Scheme 1. Reaction mechanism of ligand exchange reaction between ferrocene and benzene.

reactions with ferrocene and substituted benzenes [4]. Namely, the reaction yields under the microwave irradiation conditions at 4 minutes were approximately equal to the yield under the conventional heating conditions of 1 hour. This result is due to the fact that a high temperature locally occurred around the ferrocene- $\mathrm{AlCl}_{3}$ adduct which would efficiently absorb the microwaves.

\section{Experiment}

\subsection{Ligand Exchange Reaction}

Ferrocene $(4.0 \mathrm{mmol})$ and the heterocycles $(4.0 \mathrm{mmol})$ were dissolved in 1 , 2-dichloroethane $\left(40 \mathrm{~cm}^{3}\right)$ in a small vessel. Anhydrous aluminum (III) chloride $(8.0 \mathrm{mmol})$ was then added to the solution. The vessel was placed in a microwave reactor or in an oil bath. For the microwave irradiation, a multi-mode microwave reactor, a Shikoku Keisoku $\mu$-reactor, was used. The irradiation was carried out by a cycle of a 2 minutes irradiation and a 0.5 minute interval. The used heterocycles are shown in Scheme 2.

The products were analyzed by ${ }^{1} \mathrm{H}-\mathrm{NMR}$ and HPLC, and the yields were determined by the weight measurement of the $\mathrm{PF}_{6}$ salts [4] [5] [6].

\subsection{Measurement}

The ${ }^{1} \mathrm{H}-\mathrm{NMR}$ spectra were measured at room temperature using a JEOL A-400. The data are listed in Reference 4.

HPLC was obtained using a Shimadzu LC-10A system. The used column was Nacalai Tesque Cosmosil ${ }_{5} \mathrm{C}_{18}$ - II $(150 \mathrm{~mm} \times 4.6 \mathrm{~mm} \Phi)$, and the eluent was methanol.

\section{Results and Discussion}

As mentioned in a previous paper [4], the ligand exchange reactions with ferrocene and the fused bicyclic heterocycles under conventional heating conditions did not produce any product. However, the reaction with the fused tricyclic heterocycles produces the normal exchange products. This was due to the deflection of the $\pi$-electron on the aromatic ring caused by the electron withdrawing effect by the heteroatoms in the bicyclic compounds. In this study, the reactions 
were done under the microwave irradiation conditions (Tables 1-3).

\subsection{Ligand Exchange Reaction with Fused Five-Membered and Six-Membered Bicyclic Heterocycles}

Under conventional heating conditions, the reaction with benzothiophene proceeds, but the reactions with the other bicyclic heterocycles do not proceeds [5]. As shown in Table 1 and Table 2, benzothiophene produced the product, but the other heterocycles did not give any products under the microwave irradiation conditions. Furthermore, the reaction with benzothiophene was accelerated by the microwave.

\subsection{Ligand Exchange Reaction with Fused Tricyclic Heterocycles}

The reactions with the tricyclic heterocycles produced the products (Table 3).

\section{Fused five-membered bicyclic heterocycles}<smiles>c1ccc2[nH]ccc2c1</smiles>

Indol<smiles>c1ccc2occc2c1</smiles>

Benzofuran<smiles>c1ccc2sccc2c1</smiles>

Benzotiophene

\section{Fused five-membered and six-membered bicyclic heterocycles}<smiles>c1ccc2ncccc2c1</smiles>

Quinoline<smiles>c1ccc2cnccc2c1</smiles>

Isoquinoline

fused tricyclic heterocycles<smiles>c1ccc2c(c1)[nH]c1ccccc12</smiles>

Carbazole<smiles>c1ccc2c(c1)oc1ccccc12</smiles>

Dibenzofuran<smiles>c1ccc2c(c1)sc1ccccc12</smiles>

benzothiophene

Scheme 2. The heterocycles used in this study.

Table 1. Yields of ligand exchange reactions of ferrocene with fused five-membered bicyclic arenes under microwave irradiation or conventional heating ${ }^{\mathrm{a}, \mathrm{b}, \mathrm{c}}$.

\begin{tabular}{cccccc}
\hline \multirow{2}{*}{ Conditions } & Reaction time/min & \multicolumn{3}{c}{ Yield/\% } \\
\cline { 3 - 6 } & 5 & Indol & Benzofuran & Benzotiophene & Indene \\
\hline \multirow{2}{*}{ Microwave } & 10 & 0 & 0 & 10.0 & 29.8 \\
Conventional & 120 & 0 & 0 & - & 31.5 \\
\hline
\end{tabular}

a. solvent: 1, 2-dichloroethane, b. temperature: $80^{\circ} \mathrm{C}$, c. Fc: arene: $\mathrm{AlCl}_{3}=1: 1: 2$. 
Table 2. Yields of ligand exchange reactions of ferrocene with fused six-membered bicyclic arenes under microwave irradiation or conventional heating ${ }^{\mathrm{a}, \mathrm{b}, \mathrm{c}}$.

\begin{tabular}{ccccc}
\hline & & \multicolumn{3}{c}{ Yield/\% } \\
Conditions & Reaction time/min & Quinoline & Isoquinoline & Naphthalene \\
\cline { 3 - 5 } & 5 & 0 & 0 & 20.9 \\
Microwave & 120 & 0 & 0 & 31.8 \\
\hline
\end{tabular}

a. solvent: 1, 2-dichloroethane, b. temperature: $80^{\circ} \mathrm{C}$, c. Fc: arene: $\mathrm{AlCl}_{3}=1: 1: 2$.

Table 3. Yields of ligand exchange reactions of ferrocene with fused tricyclic arenes under microwave irradiation or conventional heating $\mathrm{g}^{\mathrm{a}, \mathrm{b}, \mathrm{c}}$.

\begin{tabular}{ccccc}
\hline \multirow{2}{*}{ Conditions } & Reaction time/min & \multicolumn{3}{c}{ Yield/\% } \\
\cline { 3 - 5 } & 4 & Carbazole & Dibenzofuran & Benzothiophene \\
\hline \multirow{2}{*}{ Microwave } & 10 & 26.4 & 27.7 & 30.4 \\
Conventional & 120 & 32.9 & 34.3 & 32.9 \\
\hline
\end{tabular}

a. solvent: 1, 2-dichloroethane, b. temperature: $80^{\circ} \mathrm{C}$, c. Fc: arene: $\mathrm{AlCl}_{3}=1: 1: 2$.

Furthermore, for these tricyclic heterocycles, shorting of the reaction time was possible by the microwave accelerating effect just like for carbocycles. Namely, for the arenes, which do not react under conventional heating conditions, the reaction also did not occur under the microwave irradiation conditions, while for the arenes, which produce the exchange products, the same products were obtained, and the accelerating effect was recognized. Furthermore, a significant increase in the temperature of the reaction solution was observed as well as in the case of the carbocycles. This means that the ferrocene- $\mathrm{AlCl}_{3}$ adduct would efficiently absorb the microwaves.

As mentioned in the introduction, the ligand exchange reaction of ferrocene proceeds via two steps [2]. The $[\mathrm{Cp}-\mathrm{Fe}]^{+}$moiety formed in the first step is considered to be a high energy species. The accelerating effect observed for the carbocycles or the present tricyclic heterocycles is due to the effective absorption by the ferrocene- $\mathrm{AlCl}_{3}$ adduct, so the first step as the rate-determining step is accelerated. Since the amount of ferrocene has decreased even in the reaction of the bicyclic compounds in which no product was obtained, the first step was expected to be accelerated by the microwaves even in this system. However, since the exchange product is very unstable in such a system [5], the transition state of the second step containing the coordination of the arenes to the $[\mathrm{Cp}-\mathrm{Fe}]^{+}$would have a high energy. Therefore, the second step becomes rate-determining, so the reaction would not be accelerated by the microwaves (Figure 1).

For the reaction using microwaves with carbazole, dibenzofuran, dibenzothiophene, which are tricyclic heterocycles, the same products as those under conventional heating conditions were obtained, and it was confirmed that the reaction time was sharply reduced. Furthermore, from the experiments in which the 
two tricyclic heterocycles were placed in the same reaction vessel, the order of reactivity was carbazole $>$ dibenzothiophene $>$ dibenzofuran, the same as under the conventional heating conditions. However, under the microwave irradiation conditions, the difference in their reactivity became negligible (Figure 2). The reason for this is considered to be the fact that the difference in the heterocycles became smaller because the reaction intermediate $[\mathrm{Cp}-\mathrm{Fe}]^{+}$obtains a high energy by the microwaves in the second step.

(a)

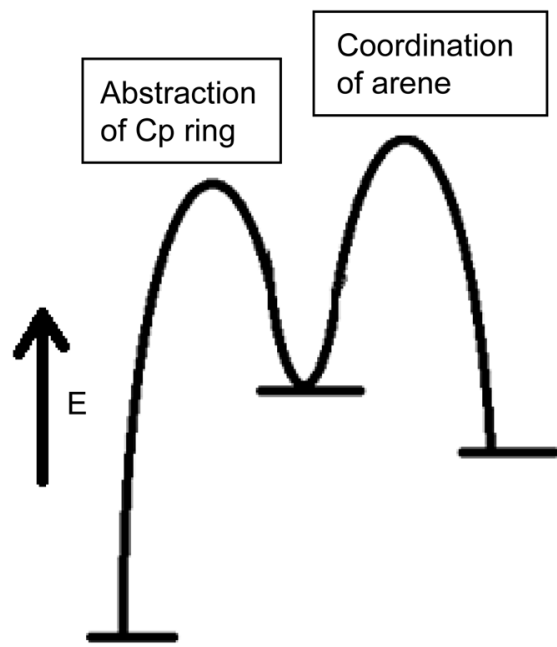

(b)

Coordination of arene

Figure 1. Plausible profiles of ligand exchange reaction with (a) the tricyclic heterocycles and (b) the bicyclic heterocycles.

microwave irradiation

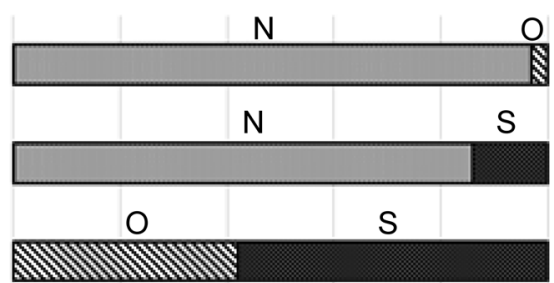

0

$40 \underset{\%}{60} \quad 80 \quad 1000$

Production ratio

$\mathrm{N}$ :<smiles>c1ccc2c(c1)[nH]c1ccccc12</smiles>

conventional heating

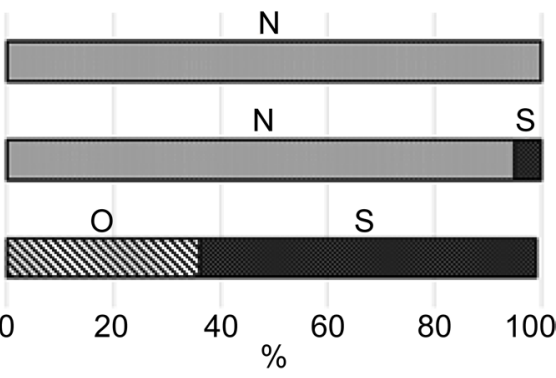

Production ratio
O:<smiles>c1ccc2c(c1)oc1ccccc12</smiles><smiles>c1ccc2c(c1)sc1ccccc12</smiles>

Figure 2. The ratio of ligand exchange products under microwave irradiation and conventional heating conditions $\mathrm{s}^{\mathrm{a}, \mathrm{b}, \mathrm{c}}$. a. solvent: 1,2 -dichloroethane, $\mathrm{b}$. temperature: $80^{\circ} \mathrm{C}, \mathrm{c}$. Fc: arene: $\mathrm{AlCl}_{3}=1: 1: 2$. 


\section{Conclusion}

The ligand exchange reaction of ferrocene is a reaction consisting of the two following steps: 1) extraction of the $\mathrm{Cp}$ ring by $\mathrm{AlCl}_{3}$, and 2) coordination of the arene to the intermediate $[\mathrm{Cp}-\mathrm{Fe}]^{+}$. The microwaves are efficiently absorbed by the ferrocene- $\mathrm{AlCl}_{3}$ adduct or the $[\mathrm{Cp}-\mathrm{Fe}]^{+}$. Therefore, it is considered that the first step, including the adduct, received a remarkable accelerating effect as in the case of the carbocycles. In the second step, the difference in reactivity depending on the type of heterocycles would be reduced, because the intermediate, $[\mathrm{Cp}-\mathrm{Fe}]^{+}$, which absorbed the microwaves, has a high energy.

\section{References}

[1] Nesmeyanov, A.N., Vol'kenau, N.A. and Bolesova, I.N. (1963) Ligand Exchange in Ferrocene. Doklady Akademii Nauk SSSR, 149, 615-618.

[2] Astruc, D. and Dabard, R. (1976) Contribution to the Study of Metallocenes. XXIV. On the Mechanism of Ligand Exchange and Complexation by Aluminum Chloride of Ferrocene and Its Alkylated and Acylated Derivatives. Journal of Organometallic Chemistry, 111, 339-347. https://doi.org/10.1016/S0022-328X(00)98142-7

[3] Kappe, C.O. (2004) Controlled Microwave Heating in Modern Organic Synthesis. Angewandte Chemie International Edition, 43, 6250-6284. https://doi.org/10.1002/anie.200400655

[4] Okada, Y. and Nakano, S. (2009) Studies on Ferrocene Derivatives. Part XVIII. Microwave Irradiation Effect on the Ligand Exchange Reaction between Ferrocene Derivatives and Aromatic Compound. Inorganica Chimica Acta, 362, 4853-4856. https://doi.org/10.1016/j.ica.2009.07.014

[5] Okada, Y., Yoshigami, Y. and Hayashi, T. (2015) Ligand Exchange Reaction of Ferrocene with Heterocycles. International Journal of Organic Chemistry, 5, 282-290. https://doi.org/10.4236/ijoc.2015.54028

[6] Okada, Y., Huruya, H. and Imori, Y. (2003) Studies on Ferrocene Derivatives. Part XVI. Steric Effects on the Ligand Exchange Reactions of Alkylferrocenes. Transition Metal Chemistry, 28, 794-799. https://doi.org/10.1023/A:1026006314010

\section{Scientific Research Publishing}

Submit or recommend next manuscript to SCIRP and we will provide best service for you:

Accepting pre-submission inquiries through Email, Facebook, LinkedIn, Twitter, etc. A wide selection of journals (inclusive of 9 subjects, more than 200 journals)

Providing 24-hour high-quality service

User-friendly online submission system

Fair and swift peer-review system

Efficient typesetting and proofreading procedure

Display of the result of downloads and visits, as well as the number of cited articles

Maximum dissemination of your research work

Submit your manuscript at: http://papersubmission.scirp.org/

Or contact gsc@scirp.org 